\title{
Pharmacognostic studies on
}

\section{Pterocarpus santalinus L.f.}

\author{
and
}

\section{Evolvulus alsinoides (L.)L.}

Wanninayaka Mudiyanselage Kapilarathna Bandara Wambatuwewa

Thesis submitted to the University of Sri Jayewardenepura for the award of Degree of Master of Philosophy in chemistry on $10^{\text {th }}$ November 2009 


\section{DECLARATION}

The work described in this thesis was carried out by me under the supervision of Prof. A. M. Abeysekera (Department of Chemistry, University of Sri Jayewardenepura ), Dr (Mrs.) P.L. Hettiarachchi (Department of Botany, University of Sri Jayewardenepura) and Mr. T. M. S.G. Tennakoon (Link Natural Products (Pvt) Ltd ) and a report on this has not been submitted in whole or in part to any University or any other institution for other Degree / Diploma
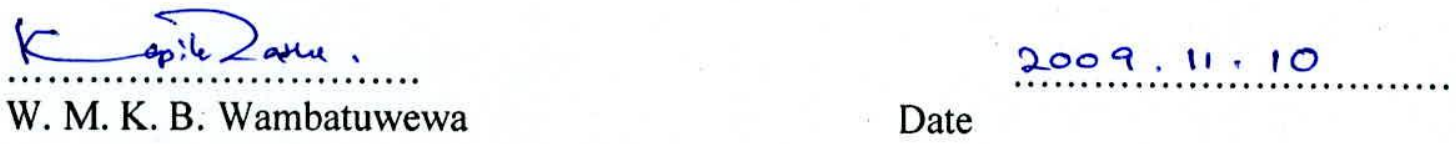


\title{
DECLARATION
}

We certify that the above statement made by the candidate is true and that this thesis is suitable for submission to the University for the purpose of evaluation

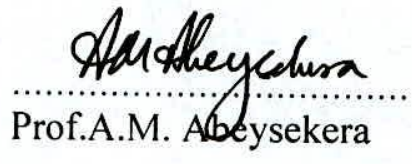

\author{
P. L. Hey \\ Dr(Mrs) P.L. Hettiarachchi
}

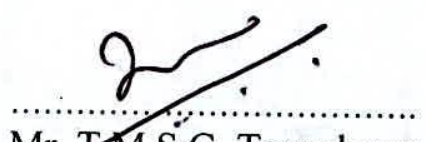

Mr. F.M.S.G. Tennakoon

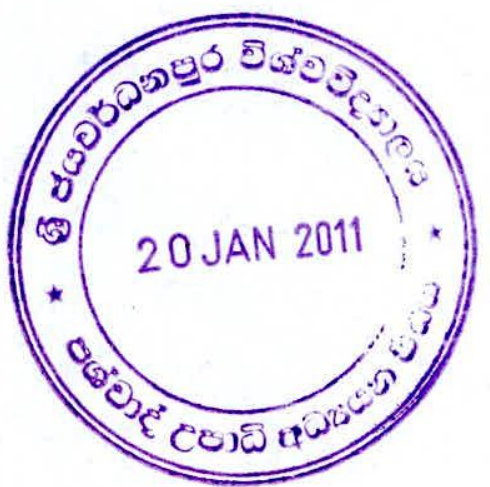


We certify that the candidate has incorporated all corrections, additions and amendments recommended by the examiners
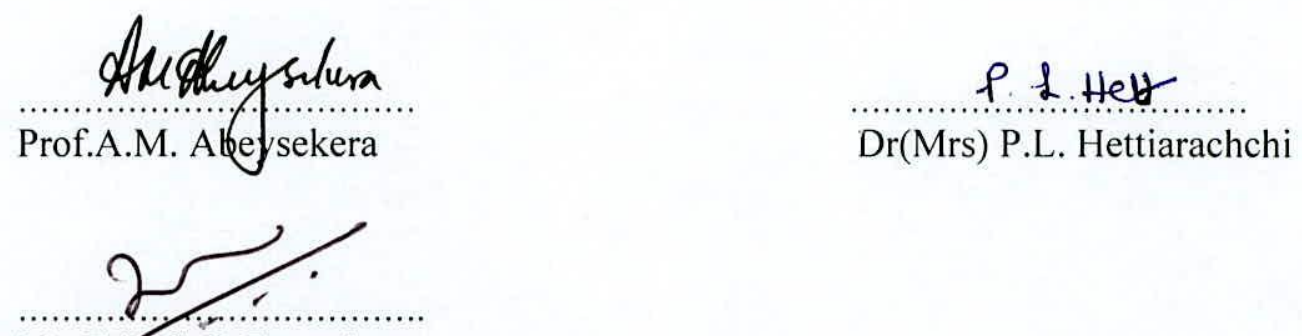

Mr. T.M.S.G. Tennakoon 


\section{CONTENTS}

TABLE OF CONTENTS

Page

LIST OF TABLES

$\mathrm{v}$

LIST OF FIGURES vii

LIST OF PLATES $\quad$ ix

LIST OF MAPS $\quad x$

ACKNOWLEDGEMENTS $\quad$ xi

ABSTRACT xiii

1. Introduction 1

1.1 Herbal medicine 1

1.2 Standardization of herbal drugs 5

$\begin{array}{lll}1.3 & \text { Scope of the thesis } & 13\end{array}$

2 Literature Review 14

$\begin{array}{lll}2.1 \quad \text { Evolvulus alsinoides(L.)L. } & 14\end{array}$

$\begin{array}{lll}2.1 .1 & \text { Phytochemistry } & 16\end{array}$

$\begin{array}{ll}2.1 .2 \text { Traditional usage } & 20\end{array}$

$\begin{array}{lll}2.1 .3 \text { Biological activity } & 20\end{array}$

$2.2 \quad$ Pterocarpus santalinus L.f. 23

$\begin{array}{lll}2.2 .1 & \text { Phytochemistry } & 24\end{array}$

$\begin{array}{lll}2.2 .2 & \text { Traditional uses } & 39\end{array}$

$\begin{array}{lll}2.2 .3 & \text { Biological activity } & 39\end{array}$

2.3 Myroxylon balsamum $\quad 42$

3 Material and Methods $\quad 44$ 
3.1. Plant material, drugs, equipments and reagents. 44

3.1.1 Plant material and drugs $\quad 44$

$\begin{array}{lll}3.1 .2 & \text { NMR spectroscopy } & 45\end{array}$

3.1.3 High performance liquid chromatography (HPLC) 45

$\begin{array}{lll}3.1 .4 & \text { Densitometry } & 45\end{array}$

$\begin{array}{lll}3.1 .5 & \text { Melting points } & 45\end{array}$

$\begin{array}{lll}3.1 .6 & \text { Microscopy } & 45\end{array}$

$\begin{array}{lll}3.1 .7 & \text { Microtome } & 45\end{array}$

3.1.8 Photography 45

$\begin{array}{lll}3.1 .9 & \text { Solvents and standards } & 46\end{array}$

3.1.10 Thin layer chromatography (TLC) 46

3.1.11 Chromatographic reagents $\quad 46$

$\begin{array}{ll}3.1 .12 & \text { Column chromatography }\end{array}$

$\begin{array}{lll}3.2 & \text { Methods } & 47\end{array}$

3.2.1 Moisture content $\quad 47$

3.2.2 Authentication of fresh plant material and preparation of $\begin{array}{ll}\text { voucher herbarium specimens } & 47\end{array}$

3.2.3 Identification of market substituents of Pterocarpus santalinus $\quad 48$

3.2.4 Preparation of reference Desandunkalkaya sample $\quad 48$

3.2.5 Screening of marker compounds of Pterocarpus santalinus. $\quad 49$

3.2.6 Isolation of pterocarpol from Pterocarpus santalinus. $\quad 49$

$\begin{array}{ll}\text { 3.2.7 Quantification of pterocarpol } & 50\end{array}$

$\begin{array}{lr}\text { 3.2.7.1 Standard curve } & 50\end{array}$ 
3.2.7.2 Preparation of pterocarpol extract from Desandunkalkaya for quantitative analysis

3.2.7.3 Method validation

3.2.7.4 Determination of pterocarpol content of market samples of

Desandunkalkaya

3.2.7.5 Preparation of Pterocarpol extract from heartwood and

sapwood of Pterocarpus santalinus for quantitative analysis.

3.2.8 Preperation of permanent mount of wood samples of

Pterocarpus santalinus and Myroxylon balsamum

3.2.9 Determination of Specific gravity of Pterocarpus santalinus and Myroxylon balsamum

3.2.10 Preparation of extract of Evolvulus alsinoides

3.2.11 Isolation of scopoletin and umbelliferone from Evolvulus alsinoides

3.2.12 TLC analysis of adulterant of Evolvulus alsinoides

3.2.13 Isolation of caffeic acid from Evolvulus alsinoides 60

3.2.14 Morphological studies of Evolvulus alsinoides

3.2.15 Preparation of temporary mounts of Evolvulus alsinoides and it'sadulterants

3.2.16 Analysis of market samples of Evolvulus alsinoides

3.2.17 Cluster analysis

4 Results and Discussion

4.1 Pterocarpus santalinus L.f 
$\begin{array}{lll}\text { 4.1.2 TLC chromatography } & 68\end{array}$

$\begin{array}{lll}\text { 4.1.3 Pterocarpol as a marker compound for Pterocarpus santalinus } & 73\end{array}$

$\begin{array}{lll}\text { 4.1.4 Spectral analysis of pterocarpol } & 77\end{array}$

4.1.5 Quantitative determination of pterocarpol in Desandunkalkaya 80

4.1.6 Microscopic studies of Pterocarpus santalinus and its substitutes $\quad 85$

4.1.7 Specific gravity of Pterocarpus santalinus and

$\begin{array}{ll}\text { Myroxylon balsamum } & 88\end{array}$

4.1.8 Polythetic key based on the wood anatomy 90

4.2 Evolvulus alsinoides (L.)L. $\quad 91$

4.2.1 Isolation of umbelliferone and scopoletine $\quad 91$

$\begin{array}{ll}\text { 4.2.2 Isolation of caffeic acid } & 93\end{array}$

4.2.3 Morphological study of Evolvulus alsinoides 96

$\begin{array}{ll}\text { 4.2.4 Adulterants of Evolvulus alsinoides } & 105\end{array}$

$\begin{array}{lll}4.2 .5 & \text { Cluster analysis } & 113\end{array}$

4.2.6 Polythetic key based on morphological characters to $\begin{array}{ll}\text { separate Evolvulus alsinoides varieties } & 114\end{array}$

5 Conclusion 115

6 References 117

$\begin{array}{lll}7 & \text { Appendix } & 127\end{array}$

$\begin{array}{ll}\text { Appendix i Data for cluster analysis } & 128\end{array}$

$\begin{array}{ll}\text { Appendix ii Spectral data of pterocarpol and caffeic acid } & 132\end{array}$

$\begin{array}{ll}\text { Appendix iii list of publications / communications } & 142\end{array}$ 


\section{LIST OF TABLES}

1. Compounds reported from Pterocarpus santalinus

2. Densitometric settings used in the determination of pterocarpol.

3. Densitometric readings obtained for the pterocarpol spot in six replicates of the reference Desandunkalkaya sample.

4. Densitometric readings obtained for the pterocarpol spot in the addition recovery experiment.

5. Densitometric readings obtained for the pterocarpol spot in different brands of Desandunkalkaya.

6. Densitometric readings obtained for the pterocapol spot in sapwood and heartwood of Pterocarpus santalinus

7. Observed ${ }^{13}$ CNMR data of pterocarpol and reported data for pterocarpol

8. Pterocarpol content of various brands of Desandunkalkaya

9. Pterocarpol content of sapwood and heartwood of Pterocarpus santalinus

10. Specific microscopic characters observed in the heartwood of Pterocarpus santalinus and Myroxylon balsamum

11. Specific gravity of Pterocarpus santalinus and Myroxylon balsamum

12. Comparison of ${ }^{1} \mathrm{H}$ NMR data and ${ }^{13} \mathrm{C}$ NMR data of Caffeic acid

13. Characters of two morphotypes of Evolvulus alsinoides as recorded during the study 
15. Seven convenient characters, which can be used to differentiate

Evolvulus alsinoides from it's adulterants 


\section{LIST OF FIGURES}

$\begin{array}{lll}\text { Figure } & \text { Page }\end{array}$

1. Standerd curve of Pterocarpol 52

2. TLC of methanol extracts of Pterocarpus santalinus, Indian Rathkihiriya, Lanka Rathhadun and Rathkihiriya

3. TLC of methanol extract of Pterocarpus santalinus, Indian Rathkihiriya, Lanka Rathhadun and Rathkihiriya

4. TLC of methanol extract of Myroxylon balsamum, Rathkihiriya and Lanka Rathhadun.

5. TLC of methanol extract of control sample, Desandunkalkaya and Pterocarpus santalinus

6. TLC of methanol extract of Pterocarpus santalinus and pterocarpol isolated from Pterocarpus santalinus

7. TLC of pterocapol visualised with AS and LB reagents

8. Variation with time of light absorption of coloured complexes of pterocarpol formed with LB and AS reagents on TLC.

9. Reflectance visible spectrum of the spot corresponding to pterocarpol after treatment of LB reagent

10. TLC of chloroform extract of Evolvulus alsinioides, Umbelliferone and Scopolatine 
11. TLC of methanol extract of Evolvulus alsinioides, Gonigyna hirta and Crotalaria prostrate

12. TLC of ethyl acetate extract of Evolvulus alsinioides and caffeic acid

13. Leaf shape of Evolvulus alsinoides, Gonigyna hirta, Crotalaria prostrata and Evolvulus glomeratus

14. Diagrams of epidermal trichomes of Evolvulus alsinoides, Evolvulus glomeratus. Gonigyna hirta and Crotalaria prostrata

15. Dendrogram generated by Unweighted Pair Group Method 


\section{LIST OF PLATES}

Plate

Page

1. Habit of Evolvulus alsinoides plant 19

2. Habit of Pterocarpus santalinus plant 38

3. Habit of Myroxylon balsamum plant 43

4. Two heartwood samples of Pterocarpus santalinus $\quad 67$

5. Heartwood sample of Pterocarpus santalinus and Myroxylon balsamum

6. Transverse section of heartwood showing the relative arrangement of axial parenchyma and vesseles of Pterocarpus santalinus and Myroxylon balsamum 86

7. Ray parenchyma in T.L.S of P.santalinus and M. balsamum 87

8. Leaves of Evolvulus alsinioides type A and type B 96

9. Some of the important taxonomic characters of Evolvulus alsinoides 97

10. Habit of two morphotypes of E.alsinoides 98

11. Habit of white flower type of E.alsinoides 103

12. Dried samples of Evolvulus alsinoides, Gonigyna hirta and

13. Leaf epidermal trichomes of Evolvulus alsinoides, Gonigyna hirta, Crotalaria prostrata and Evolvulus glomeratus . 


\section{LIST OF MAPS}

Map

Page

1. Map of Sri lanka showing sampling locations of Evolvulus alsinoides

104 


\section{Acknowledgements}

I take this opportunity to express my warmest gratitude to my supervisor, Prof. A. M. Abeysekera, Professor of Chemistry and Dean, Faculty of Applied Sciences, University of Sri Jayewardenepura, for his invaluable guidance, keen supervision, encouragement and advice extended towards the successful completion of this work through many hardships.

I wish to express my sincere gratitude to Dr. (Mrs) P. L. Hettiarachchi, Senior Lecturer, Department of Botany, University of Sri Jayewardenepura, for her keen supervision, commitment, invaluable suggestions and advice given me through out my research work.

I would also like to express my sincere thanks to my supervisor, Mr. T. M. S. G. Tennakoon, Research and Devolopment Manger, Link Natural Products (Pvt) Ltd.

I take this opportunity to express my warmest gratitude to Dr. Nugawela, Managing Director, Link Natural Products (Pvt) Ltd, for providing financial assistance for this project.

I am grateful to Prof. Tuely de Silva, Consultant, Link Natural Products (Pvt) Ltd, for his encouragement, advice and invaluable suggestions.

I wish to express my sincere gratitude to Prof. G. M. K. B. Gunaherath, Professor of Chemistry, Department of Chemistry, The Open University of Sri Lanka for providing me with NMR data from University of Queensland, Australia and his contribution to the structure elucidation. 
I also wish to thank Dr. Hiran Amarasekara and Mr Wijesinghe, Department of Forestry and Environmental Sciences, University of Sri Jayewardenepura, for providing me laboratory facilities to take wood sections.

I am grateful to Dr. Ranaweera and Mr. Sisira, Department of Food Science, Dr H. K.Ranathunga and Mr. Wijenayake, Department of Zoology, University of Sri Jayewardenepura, for providing me photographic facilities.

I also take pleasure in thanking Mr. Yapa, Mrs. Wahala and Mrs. Karunarathna for their assistance to collect plant material from the field.

I take this opportunity to thank Dr. Ranjith Gamage for sharing his extensive knowledge of Ayurveda with me and invaluable suggestions given to me through out my research work.

I am grateful to Mrs. Chandani Ranasinghe and Ms. Ajantha Gunawardene for their support given to me in numerous ways.

I also take pleasure to thank the laboratory staff of Link Natural Products (Pvt) Ltd, for their cooperation given to me through out my research work.

I take this opportunity to express my gratitude to the Department of Chemistry, University of Sri Jayewardenepura, for providing facilities to carry out my research. The cooperation of the academic, technical and non academic staff of the Department of Chemistry given to me through out the work is gratefully acknowledged.

Last but not least, I would like to express my deepest gratitude to my mother and my wife for their encouragement, understanding and kindness extended to me to achieve my goal successfully. 


\section{ABSTRACT \\ Pharmacognostic studies on Pterocarpus santalinus L.f. and \\ Evolvulus alsinoides (L.)L. \\ Wanninayaka Mudiyanselage Kapilarathna Bandara Wambatuwewa}

Pterocarpus santalinus L.f. (Fabaceae) commonly known as Rathhandun in Sinhala, is a rare and important medicinal plant. In the market, there are three red heartwoods sold as substitutes for Pterocarpus santalinus under the names of Rathkihiriya, Indian Rathkihiriya and Lanka Rathhandun. Evolvulus alsinoides (L.) L. (Convolvulaceae) commonly known as Vishnukrantiya in Sinhala, is an important medicinal plant that grows in open and grassy places. It comes to the market place in the dried form and it is often adulterated with other plant species.

The objective of the present study is to identify the morphological and anatomical characters and develop TLC methods to differentiate Pterocarpus santalinus and Evolvulus alsinoides from their adulterants found in the local market and to identify a marker compound for Pterocarpus santalinus in one of its major preparations, Desandunkalkaya.

Microscopic features such as arrangement of vessels, vessel deposits, axial parenchyma and ray parenchyma of wood in Indian Rathkihiriya were found to be identical with authentic Pterocarpus santalinus, while above features observed in Lanka Rathhandun and Rathkihiriya were identical with those of Myroxylon balsamum. The chromatograms of Pterocarpus santalinus and Indian Rathkihiriya were observed to be similar to each other, and could be easily differentiated from Lanka Rathhadun and Rathkiriya, which 
were similar to each other. Therefore, based on the results of microscopic analysis and TLC analysis, samples sold in the crude drug market as Indian Rathkihiriya was identified as Pterocarpus santalinus. Similarly Lanka Rathhadun and Rathkihiriya were identified as Myroxylon balsamum

Pterocarpol, which was identified as a marker compound for Pterocarpus santalinus, can be used to distinguish Pterocarpus santalinus from its adulterants. It can be observed clearly as blue spot at $R_{\mathrm{f}} 0.6$ (Silica / chloroform: methanol (20:1)), when sprayed with anisaldehyde / sulphuric acid reagent. This was identified as pterocarpol by Mass spectroscopy, ${ }^{1} \mathrm{H}$ and ${ }^{13} \mathrm{C}$ NMR spectroscopy. A precise, accurate, simple, and a rapid method for determination of pterocarpol content by TLC-VIS densitometric was developed. The precision was $1.513 \mathrm{CV}$ and recoveries of $96-104 \%$ were recorded in standard addition recovery experiment. Pterocarpol content of $0.06 \%$ may be recommended as a provisional standard for Desandunkalkaya.

Two species, Gonigyna hirta (Wild) Ali. and Crotalaria prostrata Roxb. were found as adulterants of Evolvulus alsinoides market samples. Those were differentiated using characters of stem (trichome), leaf (apex, base, trichome), flower (corolla shape), inflorescence (type) and fruit (type). They were stable even in the dried form. Those characters were selected out of 72 characters taken for the study. Scopoletine and umbelliferone, which were isolated from Evolvulus alsinoides were not present in the methanol extract of the adulterants. Apart form these two compounds, caffeic acid was isolated from Evolvulus alsinoides.

All Evolvulus alsinoides sample could be categorized basically into two types as type A and B based on the leaf shape and the habit. Type A, which is generally found in the dry 
zone, has Linear-oblong shape of leaf, while type B, has Oblong shape of leaf. Type A corresponds to the previously described Evolvulus alsinoides var. alsinoides and type B tallies with Evolvulus alsinoides var. hirsutus.

Polythetic keys were developed to identify varieties of Evolvulus alsinoides and also to differentiate Pterocarpus santalinus from its adulterant Myroxylon balsamum. 